\title{
A PRAGMATIC LOOK AT SCHOPENHAUER'S PESSIMISM
}

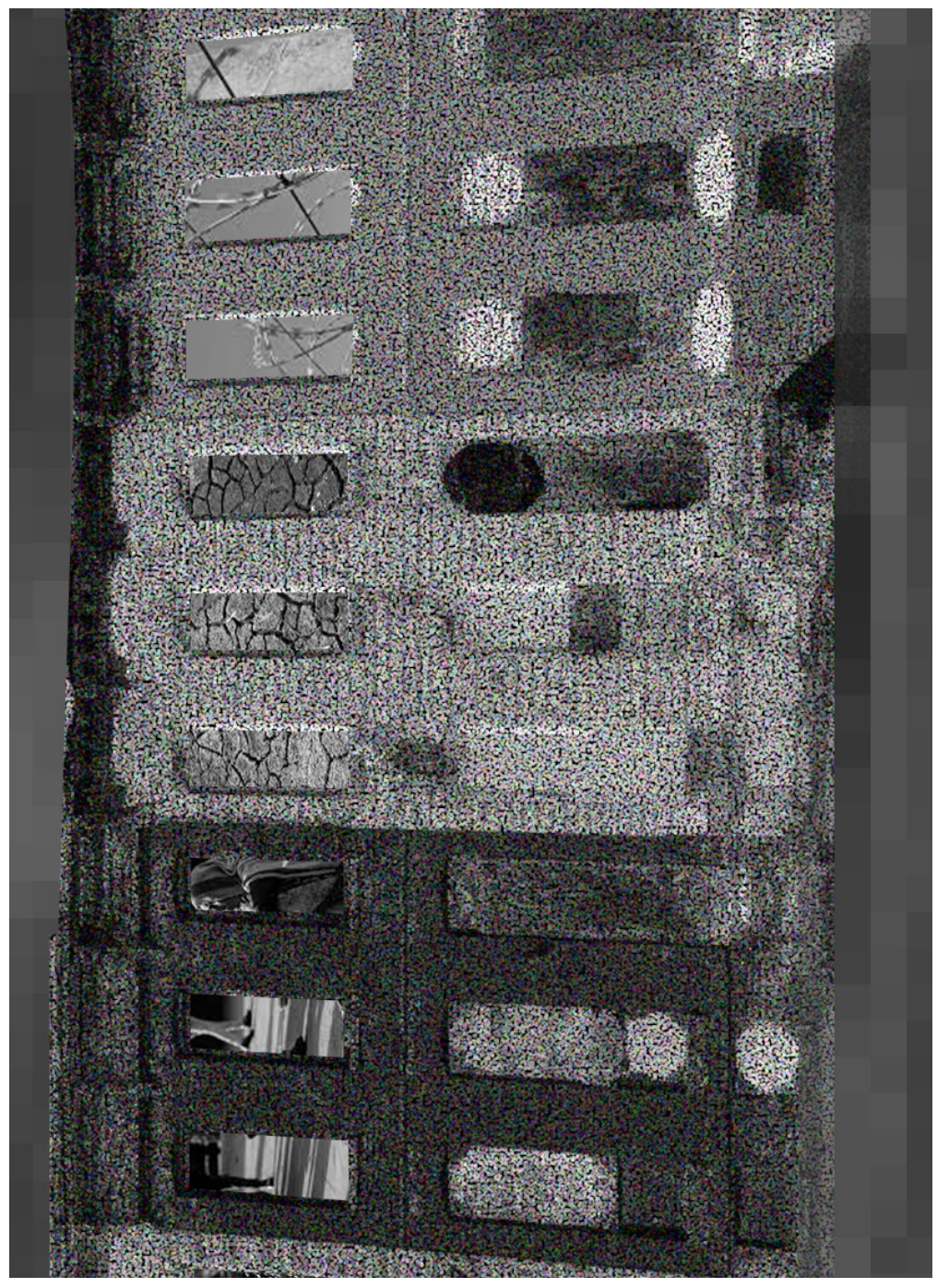

\section{ALLISON PARKER}

\section{ABSTRACT}

Schopenhauer's pessimistic philosophy is a depressing read. He writes many pages about how suffering is the norm, and any happiness we feel is merely a temporary alleviation of suffering. Even so, his account of suffering rings true to many readers. What are we to do with our lives if Schopenhauer is right, and we are doomed to suffer? In this paper, I use William James' pragmatic method to find practical implications of Schopenhauer's pessimism. I provide a model for how we are to live our lives in a suffering world, a model that provides means to reduce suffering.

\section{INTRODUCTION}

Schopenhauer introduces his pessimistic philosophy in the article "On the Sufferings of the World" by pointing out to the reader that our lives are full of suffering. He writes that "misfortune in general is the rule" by which we live our lives. ${ }^{1}$ He defines suffering as the positive force instead of as the negative. Suffering or evil is not the absence of good, but a positive force in its own right. Schopenhauer states that human pain and suffering outweigh pleasure and joy. He identifies that suffering does, however, have its uses. He writes, "if the lives of men were relieved of all need, hardship and adversity... they would be so swollen with arrogance that, though they might not burst, they would present the spectacle of unbridled folly — nay, they would go mad."2 Schopenhauer shows how humanity's expectations, hopes, fears, and desires - everything that flows from the imagination and makes up the majority of humanity's mental life — are the source of humanity's greatest sufferings just as they are the source of humanity's pleasures. Schopenhauer then lays out how different religions and traditions deal with human suffering, identifying that the Christian idea of atonement for sin is a good model, although an unpleasant one, and ends his essay by stating that we are fellow sufferers in this world and that we can recognize another's vice as being a part of the fall that has become us all, and therefore sympathize with those who do us wrong. However, perhaps there is more to gain from Schopenhauer's pessimism than sympathy for others. A look at William James' pragmatic method might show the reader what more we can get out of Schopenhauer's pessimism to make it applicable to our personal lives.

\section{JAMES' PRAGMATISM}

In a series of lectures given at the Lowell Institute in Boston in 1906 and at Colombia University in New York in 1907, William James

1 Arthur Schopenhauer, "On the Sufferings of the World," in The Essays of
Arthur Schopenhauer: Studies in Pessimism, trans. T. Bailey Saunders
(Blackmask Online, 2004), 2.
2 Schopenhauer, "On the Sufferings," 2.


defined the pragmatic method as a way in which "to try to interpret each notion by tracing its respective practical consequences." 3 The pragmatic method is a way to view philosophical theories in light of which theories are the most practical or which ones are the most useful for people. In the preface of these lectures, James asserts that most of what we learn from the world comes from our experience, not what we read in books. This paper will attempt to use James' pragmatic method to view the pessimistic philosophy of Schopenhauer chiefly expressed in his essay, "On the Sufferings of the World." If the world is full of suffering and misfortune, as Schopenhauer argues, then we must find ways of dealing with this painful world. We must understand the implications this metaphysical view has for our lives and then attempt to see how we can remedy some of the problems of our world through practical measures that we can implement in our daily lives. This paper will focus mostly on suffering rather than a full account of Schopenhauer's pessimistic philosophy, since suffering is the most concrete and evident aspect of his pessimism that we are faced with in our daily lives.

\section{II. "ON THE SUFFERINGS OF THE WORLD"}

Schopenhauer opens "On the Sufferings of the World" by noting that it is absurd to view all of the suffering in the world "as serving no purpose at all and the result of mere chance." 4 Shortly after that opening paragraph, he states that "misfortune has its uses" in that it keeps us steady and sane. ${ }^{5}$ Schopenhauer uses the Christian model of atonement for sin, not out of any responsibility toward the religion or out of any reverence to God, but because the understanding of suffering in the world being the fault of human nature and thus falling under human responsibility is a useful way of picturing the suffering of the world. Schopenhauer ends his essay in a call to action, telling his reader that, in light of his discussion about the sufferings of the world, we should have "tolerance, patience, regard, and love of neighbor." Not only does Schopenhauer give us an argument for his metaphysical view, but he recognizes that his view has implications on how we should live our lives and treat each other. However, Schopenhauer's main concern in this essay is to show that suffering is the general rule by which the world is maintained rather than to give us a plan on how to live in such a world. This paper will attempt more of the latter-showing how we are to live if we are to adopt Schopenhauer's account of suffering.

3 William James, Pragmatism: A New Name for Some Old Ways of Thinking (New York: Longmans, Green, and Co., 1921), 45

4 James, Pragmatism, 2.

James, Pragmatism, 2

Schopenhauer, "On the Sufferings," 9
Schopenhauer addresses various topics in the realm of suffering, each of which must be dealt with if we are to understand the practical impliacations of his work. He addresses the lives of animals and how their lives relate to human lives, the issue of procreation and whether or not it is justifiable to bring life into a world in which it is doomed to suffer, and the role that reputation - or what we think other people think about us - plays in our suffering. Since these are the topics that Schopenhauer concentrates on, each of these topics will get a section in this paper which explains his views and attempts to show how we can interpret each in a pragmatic way. We can use the lives of animals as a model for how we could reduce suffering, even though there is a fundamental difference between animals and humans: the Will. We can justify introducing new humans into the world of suffering by differentiating various types of suffering and realizing that we have the power, in some cases, to exchange one type for another. We can reduce the pain caused by our thoughts about the opinions of others by viewing our own lives on their own, without comparing them to the lives of others. The suggestions offered at the end of the following sections amount to recognizing the ways in which we suffer. Schopenhauer might be right that suffering is the norm, but if we can recognize the cause of many of our sufferings, we can be more conscious about them and make decisions that attempt to reduce the amount of suffering we and others endure. We know we suffer, but we do not always know why. Understanding why will shed light on small things we can do to adjust our views and actions to reduce suffering.

\section{ANIMAL LIFE AS A MODEL}

Schopenhauer offers the way animals experience suffering and pleasure as a contrast to human experience. Animals live in the present moment, being able to enjoy life without fears, regrets, or other mental phenomenon to disturb their peace of mind. Schopenhauer seems to envy the ability of animals to enjoy the present moment undisturbed. He states that when we hope for something and look forward to it, we enjoy it less when it comes along because it often falls short of our expectations. Animals do not suffer this experience of disappointment since they do not hope toward something better in the future. They are allowed to be surprised and pleased by every pleasant moment instead of being disappointed that it did not match their expectations. However, he also acknowledges that animals pay a price for this peace of mind. They are unable to hope in times of trouble and unable to hold onto pleasant memories when they are suffering, making their suffering even more painful as a result.

Should we attempt to be more like animals, not allowing our fears or hopes to take away from the small pleasures of life? If we were to 
take up such a method of thinking, some might say we would lose our sense of purpose, which is a higher pleasure than the physical pleasure that animals enjoy. We would also be unable to combat our moments of suffering with hopes and pleasant memories that might give us strength and courage. However, if we were able to enjoy the present moment like animals do—not expecting anything or fearing anything-but also able to hope in times of trouble, we might be able to keep a little bit of the best of both worlds This is a possible practical implication. At least in our pleasant moments, if we can attempt to forget our fears and regrets, we might be able to enjoy those moments a little more, which is some small progress.

There is a fundamental way in which humans and animals are different which is relevant to our ability (or inability) to enjoy the present moment as animals do: the Will. Schopenhauer writes that "Will is the lord of all worlds." By this he means that Will is in reality a unity but that individuals fragment it, breaking it up, by viewing themselves as individuals with independent wills. Each human, then, has an individual will, but it is a broken fragment of the real Will, constantly striving for that endless, timeless, completely free reality without ever being able to achieve it because it is not whole. Humans cannot view life as cats and dogs do because they are aware of themselves as individuals with individual wills, which automatically dooms them to a hopeless life of frustration. What we can do, though, is recognize that we are not the only broken fragments of Will. All other humans share that quality with us. That thought should make us feel a little less alone and a little more understanding of others.

\section{PROCREATION}

If life is determined by suffering, is it better to not exist at all? Would we be better off to annihilate such a world full of pain and hardship? These are questions that Schopenhauer brings up in his essay. Even if we do not have a red button to push to end the worldalthough there are some who might, in fact, have such a power now - these questions are still important to consider because most of us do have the ability to continue the human race in some small degree. Perhaps this is a more applicable question to our own lives: is it right to bear children into such a world for them to suffer as we have suffered-or, as Schopenhauer puts it, "would not a man rather have so much sympathy with the coming generation as to spare it the burden of existence?" 8 We do continue to bear children even though we know they will suffer, but this could be due to our own faulty nature,

7 Arthur Schopenhauer, "The Vanity of Existence," in The Essays of

Arthur Schopenhauer: Studies in Pessimism, trans. T. Bailey Saunders

(Blackmask Online, 2004), 10.

Schopenhauer, "On the Sufferings," 3. unable to rationalize the consequences of our actions, especially those actions which afford us a great sense of physical pleasure in a world that continually denies us such pleasures. If we make it our goal to alleviate suffering if we can, it seems like refusing to have children would be one step toward that goal, if those children will only add to the amount of people suffering already.

However, to remove suffering from the world is not the same as to remove the people who suffer. It might be true that no existence at all is better than an existence filled with pain and suffering, although I hesitate to admit that positively, but the possibility of an existence without pain or suffering-or one at least with more pleasure than pain-is itself more valuable than nonexistence. The goal is not to achieve "no suffering at all," but rather "no suffering in people's lives." Removing or preventing life does not solve the problem. We must find other ways to alleviate suffering, if that is our goal. We must at least try a little longer, although it might be a possibility that our goal is unreachable and a complete end to existence is the only remedy. The practical implication of this discussion is that preventing new people from being born into a suffering world or ending the existence of people who are already suffering should not be done because doing those things also removes our possibility of life without suffering, which is the true goal.

However, as Schopenhauer describes, there is a purpose for suffering. He states that "a certain amount of care or pain or trouble is necessary for every man at all times. A ship without ballast is unstable and will not go straight."'9 Suffering and pain keep us in check. They teach us lessons and help us to grow. If we did not have suffering to keep us occupied, we would find ways to entertain ourselves, which might be more devastating than the suffering we are currently subject to. There are countless stories of people who were only able to accomplish great feats because their suffering made them strong, opening their eyes to things they would not have seen otherwise. If suffering is helpful, though, perhaps we should allow it and stop trying to relieve ourselves from it. However, not all types of suffering are helpful, and perhaps we can choose. We can barter for the kind of suffering that will help us the most. People do this all the time: they choose to toil and work to avoid the suffering of starvation, thus exchanging one form of suffering (labor) for another (starvation). We can choose to work and struggle to end certain kinds of suffering. In this way, we can at least take comfort in the fact that our suffering has a purpose, even if it is just to alleviate another form of suffering. We can also take comfort in the fact that we are actively choosing to engage in it for a higher cause. If Schopenhauer is right, we will never reach a point where we will not have any suffering at all, so we will always have plenty to keep us busy. We can choose to make progress even though we will

9 Schopenhauer, "On the Sufferings," 2. 
suffer the whole way and even though we will never reach total freedom from suffering.

\section{REPUTATION}

Schopenhauer discusses one factor of our ability for reflection that contributes greatly to human pleasure and pain: "ambition and the feeling of honor and shame; in plain words, what he thinks about the opinion other people have of him." 10 Our concern for our reputation takes up a good deal of our thoughts, directs and controls our actions, and constitutes a large quantity of our anxiety: we worry about what people think of us. Most people differentiate between a healthy concern for reputation and an unhealthy one. It is perhaps admirable to desire to please people, make them happy, and be concerned if they think ill of us. However, this concern for other people's opinions is often taken to the extreme, where vanity and pretentiousness are the vices of an exaggerated concern for one's reputation. Anxiety about what other people think of oneself is also a great cause of depression if one is unable to shake the disturbance of being disliked or disapproved of, or the false belief that one is disliked or disapproved of.

One solution could be to disregard the opinion of others when that opinion concerns oneself. However, this solution can have downfalls. A complete disregard of the opinions of others prevents people from growing, from being able to accept constructive criticism, or from changing one's actions based on the opinion of others in a healthy way that better serves the opinion-holder as well as the subject. I turn to Marcus Aurelius to provide a solution. Marcus Aurelius, in his Meditations, wrote that Epictetus said that "man must discover an art (or rules)... in respect to his movements...that they have regard to the value of the object." 11 The "value of the object" here is contrasted with "the perceived value of the object." Instead of being concerned with how our movements and actions are perceived, we must consider their actual worth. That worth is gauged by how they benefit ourselves and those around us. If one's actions give him pleasure because they impress others, that in itself has no real value. If one's actions help others and provide an example for his neighbors to live by to better their own lives, then those actions do have value. Reputation itself is not bad or harmful, but it must be considered in a way that best helps those around us and works toward easing their pain and suffering. It is true that reputation is the source of much of our suffering, but we can attempt to use reputation as a tool to provide others with an example of how to live-not simply because impressing others gives us pleasure, but because to alleviate suffering, we must help our neighbors to see new

10 Schopenhauer, "On the Sufferings," 4.

11 Marcus Aurelius, Meditations (Mineola, New York: Dover Publications, 1997), 11; 137. ways to live their lives that reduce suffering for themselves and those around them.

Another great source of discontent is the tendency to compare one's own lot to the lot of others. If one sees that his neighbor suffers less than he does, he will feel indignation at the inequality of life and suffer more because of the comparison. Again, one must consider Marcus Aurelius' use of Epictetus' statement about the true value of an object. In order to avoid the feeling of inequality one feels when comparing one's misfortune to the fortune of others, one must consider his own life on its own, deciding its value independent of the comparison it has to the lives of others, and then deciding on methods to improve that life. Schopenhauer is right to say that we suffer when we consider the opinions of others too much. He would also be right in saying we suffer when we spend too much time on our opinions of the lives of others. Both of these sufferings, however, can be remedied by shifting one's gaze to the actual value of one's actions and directing one's movements toward increasing that actual value.

\section{CONCLUSION}

Schopenhauer makes a strong case for his pessimistic philosophy. We cannot deny how much we suffer in our lives, and we cannot fail to see that others suffer as well. For those who agree with Schopenhauer that suffering is the positive force of life, we must then ask ourselves how we will continue living in such a world where pain is the norm. By reading Schopenhauer's essay in a pragmatic way-viewing his concepts in terms of precepts for our behavior-we can attempt to alleviate the suffering we all endure. I am not doing anything here that Schopenhauer has not already thought of, for he ends his essay telling his reader to sympathize with others and act in a way that produces the least amount of suffering for those who are already experiencing so much suffering. However, we can add to this statement and develop a model for how we are to live our lives in a suffering world by analyzing his various points and considering the practical implications of them, by "try[ing] to interpret each notion by tracing its respective practical consequences." 12 Philosophy need not be limited to a select group of professors who think and write on profound questions about the universe that others not trained in philosophical discourse cannot understand. Philosophy can, and should, be understood as a search for truth for the purpose of living our lives in the best way possible. 


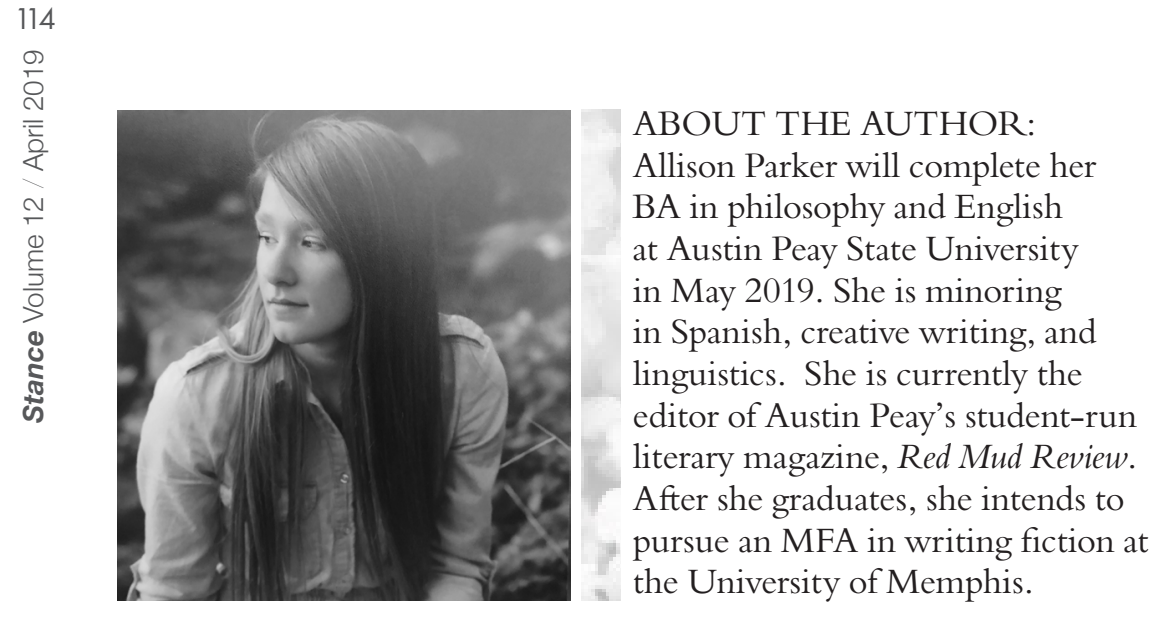

Allison Parker will complete her

ophy and English

in May 2019. She is minoring

in Spanish, creative writing, and

linguistics. She is currently the

editor of Austin Peay's student-run

the University of Memphis.

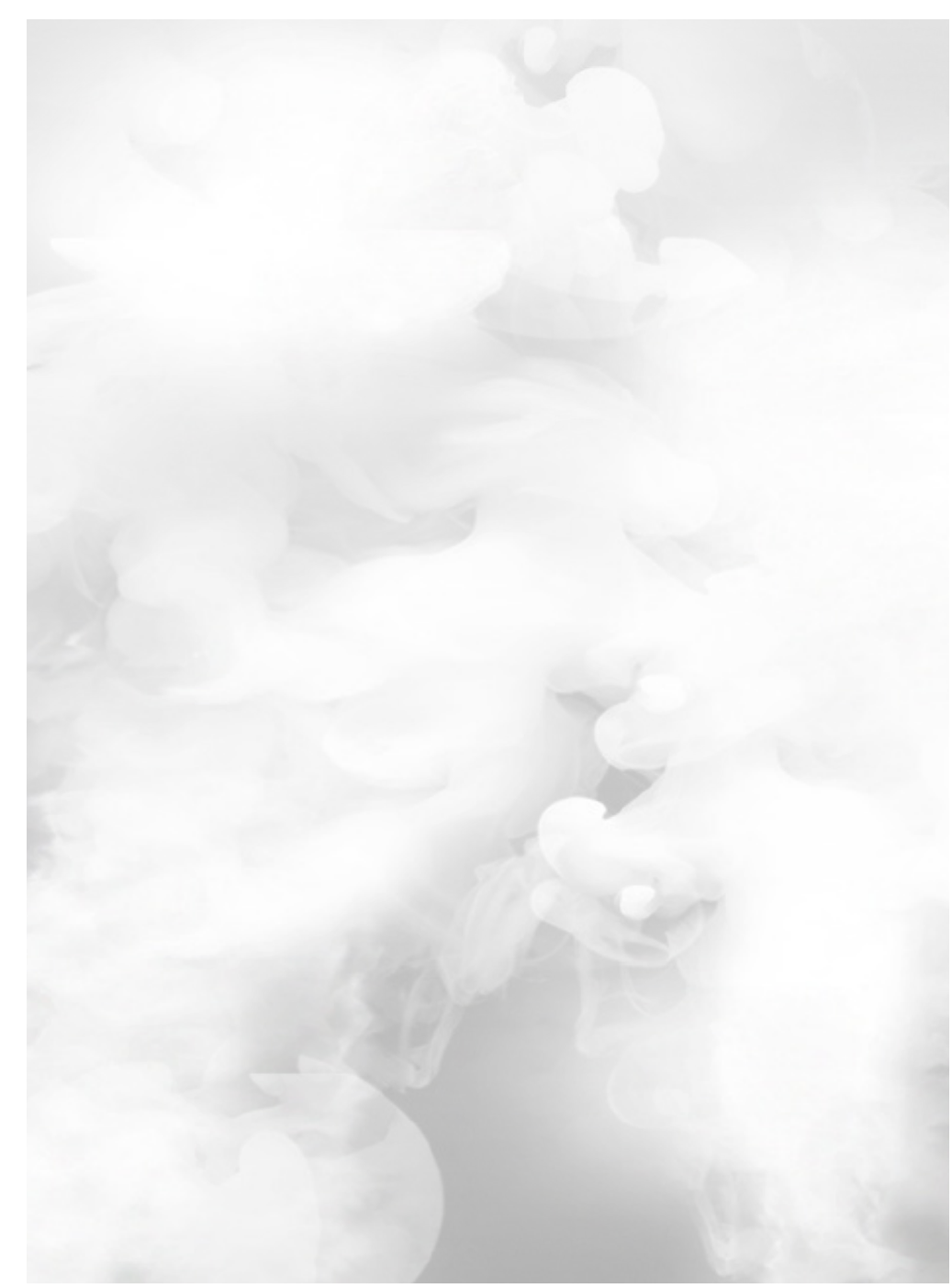

